Research Article

\title{
Thermal Performance Evaluation of a Double Pipe Heat Exchanger Installed in a Biomass Gasification System
}

\author{
Nwabunwanne Nwokolo (iD, Patrick Mukumba iD, and KeChrist Obileke \\ Department of Physics, University of Fort Hare, P. Bag X1314, Alice 5700, South Africa \\ Correspondence should be addressed to Nwabunwanne Nwokolo; nnwokolo@ufh.ac.za
}

Received 2 May 2020; Revised 26 June 2020; Accepted 15 July 2020; Published 1 August 2020

Academic Editor: Abdullah A. Kendoush

Copyright (C) 2020 Nwabunwanne Nwokolo et al. This is an open access article distributed under the Creative Commons Attribution License, which permits unrestricted use, distribution, and reproduction in any medium, provided the original work is properly cited.

\begin{abstract}
Heat exchangers are widely used for heat recovery purposes in many industrial applications such as gasification systems. In a biomass gasification system situated at Melani village in Eastern Cape of South Africa, a significant quantity of heat energy is lost during syngas cooling. Thus, a heat exchanger was constructed and installed in the gasification system for the purpose of heat recovery. Therefore, the aim of this study is to evaluate the performance of the heat exchanger under variable operating conditions for counterflow and parallel flow configurations. The experimental investigation was carried out on a double pipe heat exchanger as the downdraft gasifier system operated on a wood consumption rate of $180 \mathrm{~kg} / \mathrm{h}$. The heat exchanger was installed at the exit point of the syngas in the gasifier, and water served as the cooling fluid. Inlet and outlet temperatures of the hot syngas and cooling water (fluids) were measured using thermocouples at variable flow rates. Experimental data were processed using energy equations to determine vital performance parameters (overall heat transfer coefficient, effectiveness, and log mean temperature difference). The findings showed that optimum heat exchanger effectiveness of 0.55 was determined at a mass flow rate of $0.07 \mathrm{~kg} /$ s. In addition, counterflow configuration was found to be approximately $14 \%$ more effective than the parallel flow configuration. This is attributed to the relative direction of the fluids in the configurations of both flows. The study recommends that double pipe heat exchanger is suitable for recovering heat from the gasification system.
\end{abstract}

\section{Introduction}

Heat recovery is an essential part of any engineering application requiring the efficient transformation of energy from one form to another. This is achieved with the aid of a device called heat exchanger, which is widely used in energy industries, automobile industries, food industries, chemical process industries, and power plants. In energy transformation technologies such as biomass gasification, where heat can be a product or byproduct, heat recovery using heat exchanger is a necessity [1]. Biomass gasification involves the conversion of solid biomass into gaseous fuel in the absence of oxygen and at high temperature. Biomass gasification plant generally comprises different systems that make up a unit, namely, feeding system, gasifier/reactor, cleaning systems such as cyclone, and syngas cooling systems such as gas scrubber. These individual systems constitute to the overall efficiency of the gasification plant [2].
In the system Johansson biomass gasifier (SJBG), which is the focus of this study, hot syngas when generated from the gasifier will first go through the cyclone for purification purposes. The syngas produced exits the gasifier at a very high temperature because the gasifier is of downdraft type. Thus, significant quantity of heat can be recovered from the syngas prior to or during the cleaning process using a heat exchanger system. Studies on the efficient use of heat exchanger systems for the recovery of waste heat in gasification technology are scarce. Moreover, in downdraft gasifier very few studies focused on the application of heat exchanger at the cyclone section for heat recovery purposes. Consequently, more research is required in this context.

The idea behind the recovery of heat energy from syngas before it goes through the cleaning process is to harness the heat that is ordinarily wasted during the cleaning process and to improve the overall conversion efficiency of the 
gasification system. A previous study carried out on the system Johansson biomass gasifier showed that the produced syngas leaves the gasifier with the temperature range of $300^{\circ} \mathrm{C}-400^{\circ} \mathrm{C}$ and is cooled at the scrubber to a temperature of about $25^{\circ} \mathrm{C}$. This results in significant energy loss which impacts on the thermal efficiency of the gasification system. Overall, there is obvious need to explore the integration of a heat exchanger system into SJBG for proper and efficient recovery of gasification waste heat for adequate energy management in the syngas production. Hence, we hypothesized that the integration of a double pipe heat exchanger will to a higher degree enhance the recovery of heat in the system. A double pipe heat exchanger was used due to its maintenance ease in situations of fouling. The syngas emerging from the gasifier contains carbon particles that can easily clog the surface of the heat exchanger, thereby creating a fouling condition. Hence, a double pipe heat exchanger with an easy cleaning capability was chosen. Moreover, the choice and integration of double pipe heat exchanger kept the alteration made to the gasification system at a minimal level. In the present study, by combining engineering process and design, we aimed to construct and integrate a double pipe heat exchanger around the cyclone section of the gasification system and evaluate the performance of the heat exchanger in terms of its ability to recover heat energy.

\section{Double Pipe Heat Exchanger Applications}

Double pipe heat exchanger (DPHE) is regarded as one of the simplest types of tubular heat exchanger. It is made up of concentric pipes that are separated by mechanical closures. Double pipe heat exchangers are relatively cheap to construct and require minimal maintenance. They are used in high temperature and high pressure applications for sensible heating or cooling [3]. In recent years, several studies have been carried out to evaluate and improve the performance of heat exchangers in general. High performance heat exchangers are required in order to increase the efficiency of most industrial applications where heat exchangers are of great necessity. A recent study described the principle techniques involved in augmentation of single phase heat transfer in a double pipe heat exchanger. A metallic tape was twisted along its longitudinal axis and inserted in the tube to create a swirl flow. The result obtained in the study showed that the heat transfer coefficient for the tube with twisted tape was higher compared to the tube without twisted tape [4].

Another study presented an experimental comparison of different types of heat transfer enhancement techniques in a double pipe heat exchanger using extended surfaces. The inner tube of the heat exchanger was modified by providing a fin, spiral rod, and annular disk. The annular method showed a higher heat transfer compared to the fin and spiral rod at varying flow rates [5]. Heyhat et al. [6] evaluated the effects of air flow rate injection and angle positioning of the heat exchanger on the thermal performance of a double pipe heat along with exergy analysis. The findings suggested that air injection can be used as an active method of improving heat transfer in double pipe heat exchanger. An experimental investigation of the effect of fluid flow rate on the performance of a parallel flow extended plate heat exchanger was conducted. Parameters considered in the study include thermal efficiency, overall heat transfer coefficient, flow rate, and Reynolds number. The thermal efficiency and overall heat transfer coefficient showed an increase with the increase in flow rate. However, the study suggested that more increase in the hot fluid flow rate will influence the thermal efficiency more compared to cold fluid flow rate.

\section{Description of the Gasification System}

A system Johansson biomass gasifier is made up of the gasifier, cyclone, gas scrubber, particle interference filter, safety filter, and gas engine as shown in Figure 1. The gasifier, also referred to as reactor, is the major component of any biomass gasification plant. Biomass gasifiers come in various types: fixed bed, fluidized bed, and entrained flow. These biomass gasifier classifications are dependent on biomass material type, properties, and end use applications. In fixed bed gasifier, feedstocks (biomass material) are gasified at high temperature and pressures up to 30 bar [7]. Fixed beds are further classified into downdraft, updraft, and cross draft. These classifications are dependent on the interaction that exists between gasification agent and biomass materials. For downdraft, the solid biomass and gasification agent both move in a downward concurrent manner, hence its name. During gasification in the downdraft gasifier, biomass materials are subjected to different reaction zones: drying zone, pyrolysis zone, oxidation zone, and reduction zone [8]. These zones have different temperature ranges that are associated with it. The moisture content of the biomass materials is driven out at the drying zone around a temperature of about $150^{\circ} \mathrm{C}$. At the oxidation zone, the heat needed to drive the rest of the processes in the other zones is generated, while the individual gases that make up the syngas are formed at the reduction zone. The chemical reactions involved in the gasification process are summarized in Table 1 [9-12].

The chemical reactions in Table 1 result in the production of a mixture of gases that exit the gasifier as a single gas stream referred to as syngas; it first goes through the cyclone in a tangential manner due to its tangential inlet. On entering the cyclone, the syngas stream swirls around, thereby forcing the particles in the gas stream to the outer wall in a downward manner. These particles are then collected at the bottom of the cyclone and the clean syngas goes through the exit pipe at the top. At the cyclone, large particles of sizes above $5 \mu \mathrm{m}$ are removed efficiently. However, particles of submicron sizes are also removed, but with lesser efficiency as compared to the previous one [13]. In SJBG, about $80 \%$ of these large sized particles are removed when the system is operating on a full load. As the syngas makes its way through the cyclone, some significant portion of the heat energy in the syngas is lost to the atmosphere through the walls of the cyclone. A thermographic image of the cyclone reported in a previous study indicated that the surface temperature of the cyclone reached up to $200^{\circ} \mathrm{C}$ [14]. From the cyclone, the syngas goes to the wet scrubber for 


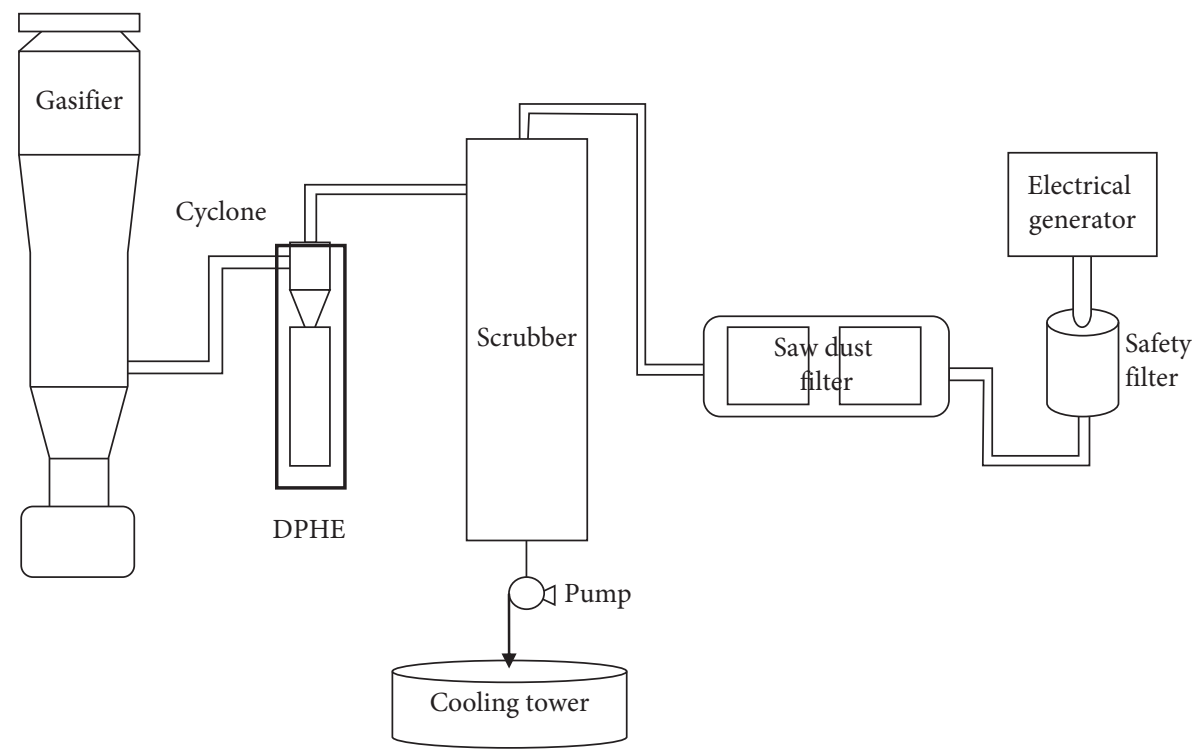

Figure 1: Schematic diagram of the gasifier unit integrated with heat exchanger.

TABLE 1: Chemical reactions involved in gasification process.

\begin{tabular}{|c|c|c|}
\hline Reaction & $\begin{array}{l}\text { Heat of } \\
\text { reaction }\end{array}$ & Type of reaction \\
\hline $\mathrm{C}+\mathrm{CO}_{2} \longrightarrow 2 \mathrm{CO}$ & $172.5 \mathrm{~kJ} / \mathrm{mol}$ & Boudou \\
\hline $\mathrm{C}+\mathrm{H}_{2} \mathrm{O} \longrightarrow \mathrm{CO}+\mathrm{H}_{2}$ & $131.3 \mathrm{~kJ} / \mathrm{mol}$ & Vater gas \\
\hline $\mathrm{C}+2 \mathrm{H}_{2} \mathrm{O} \longrightarrow \mathrm{CO}_{2}+2 \mathrm{H}_{2}$ & $90.2 \mathrm{~kJ} / \mathrm{mol}$ & $\begin{array}{l}\text { Water gas } \\
\text { secondary }\end{array}$ \\
\hline $\mathrm{C}+2 \mathrm{H}_{2} \longrightarrow \mathrm{CH}_{4}$ & $-74.9 \mathrm{~kJ} / \mathrm{mol}$ & Methanation \\
\hline $\mathrm{CO}+\mathrm{H}_{2} \mathrm{O} \longrightarrow \mathrm{CO}_{2}+\mathrm{H}_{2}$ & $-41.2 \mathrm{~kJ} / \mathrm{mol}$ & Water gas shift \\
\hline $\mathrm{CH}_{4}+\mathrm{H}_{2} \mathrm{O} \longrightarrow \mathrm{CO}+3 \mathrm{H}_{2}$ & $206.2 \mathrm{~kJ} / \mathrm{mol}$ & Steam reforming \\
\hline $\mathrm{CH}_{4}+\mathrm{CO}_{2} \longrightarrow 2 \mathrm{CO}+2 \mathrm{H}_{2}$ & $247.4 \mathrm{~kJ} / \mathrm{mol}$ & Dry reforming \\
\hline
\end{tabular}

further cooling. The cooling of syngas at the scrubber involves spraying of water over a scrubbing medium consisting of a low resistance, but porous large surface area. This scrubbing medium usually consists of a coarse or even graded charcoal. The water used in the scrubber is recycled through an ambient pond. Table 2 presents a summary of the gasification process parameters used.

\section{Materials and Methods}

4.1. Design and Development of the Heat Exchanger. The first step taken was to determine a feasible design of heat exchanger and an appropriate position for its integration into the gasification system. Considering that the cyclone separator is the first entry point for the hot syngas stream and that its surface temperature reaches up to $200^{\circ} \mathrm{C}$, cyclone separator was chosen as the appropriate position for integration of the heat exchanger. An indirect contact heat exchanger (double pipe type) was decided on so that no direct interactions exist between the syngas and water (fluids) when passing through the heat exchanger. The presence of particulate matter and sulphur compounds in the syngas would pose a danger if it were to be a direct contact type. A double pipe heat exchanger was used due to its maintenance ease in situations of fouling. The syngas emerging from the
TABLE 2: Gasification process parameters.

\begin{tabular}{lc}
\hline Parameters & Values \\
\hline Gasifier feedstock consumption rate & $180 \mathrm{~kg} / \mathrm{h}$ \\
Moisture content & $14 \%$ \\
Feedstock size & $0.075 \times 0.068 \times 0.043 \mathrm{~m}$ \\
Gasifier outlet temperature & $350^{\circ} \mathrm{C}$ \\
\hline
\end{tabular}

gasifier contains carbon particles that can easily clog the surface of the heat exchanger, thereby creating a fouling condition. Hence, a double pipe heat exchanger with an easy cleaning capability was chosen. Moreover, the choice and integration of double pipe heat exchanger kept the alteration made to the gasification system at a minimal level. The dimensions of the cyclone were put into consideration in the design and development of the heat exchanger. The three-dimensional view of the designed heat exchanger is shown in Figure 2.

The double pipe heat exchanger (DPHE) with dimension $0.51 \times 0.48 \times 1.36 \mathrm{~m}$ presented in Figure 2 was made using Autodesk software package. A hot rolled mild steel sheet was employed in the actual fabrication of the heat exchanger prior to its integration into the gasifier unit. Some other materials used for the fabrication of the heat exchanger include angle iron mild steel for closing the four edges, pressure release valve, sealing materials such as silicon, electrical equipment such as thermocouples, and welding machine. The mild steel sheet was cut into four rectangular pieces and was used in the formation of the heat exchanger. The sealing materials were used to seal up any form of leakage that might exist after the welding process. Three water control valves were welded to the body of the heat exchanger at the top, middle, and bottom for water inlet and outlet. This was aimed at ensuring adequate flow of water for uniform transfer of heat and for adjusting the flow direction. A pressure release valve was also installed at the top of the heat exchanger to regulate pressure build-up within the heat exchanger. Thermocouples were also inserted into the heat 

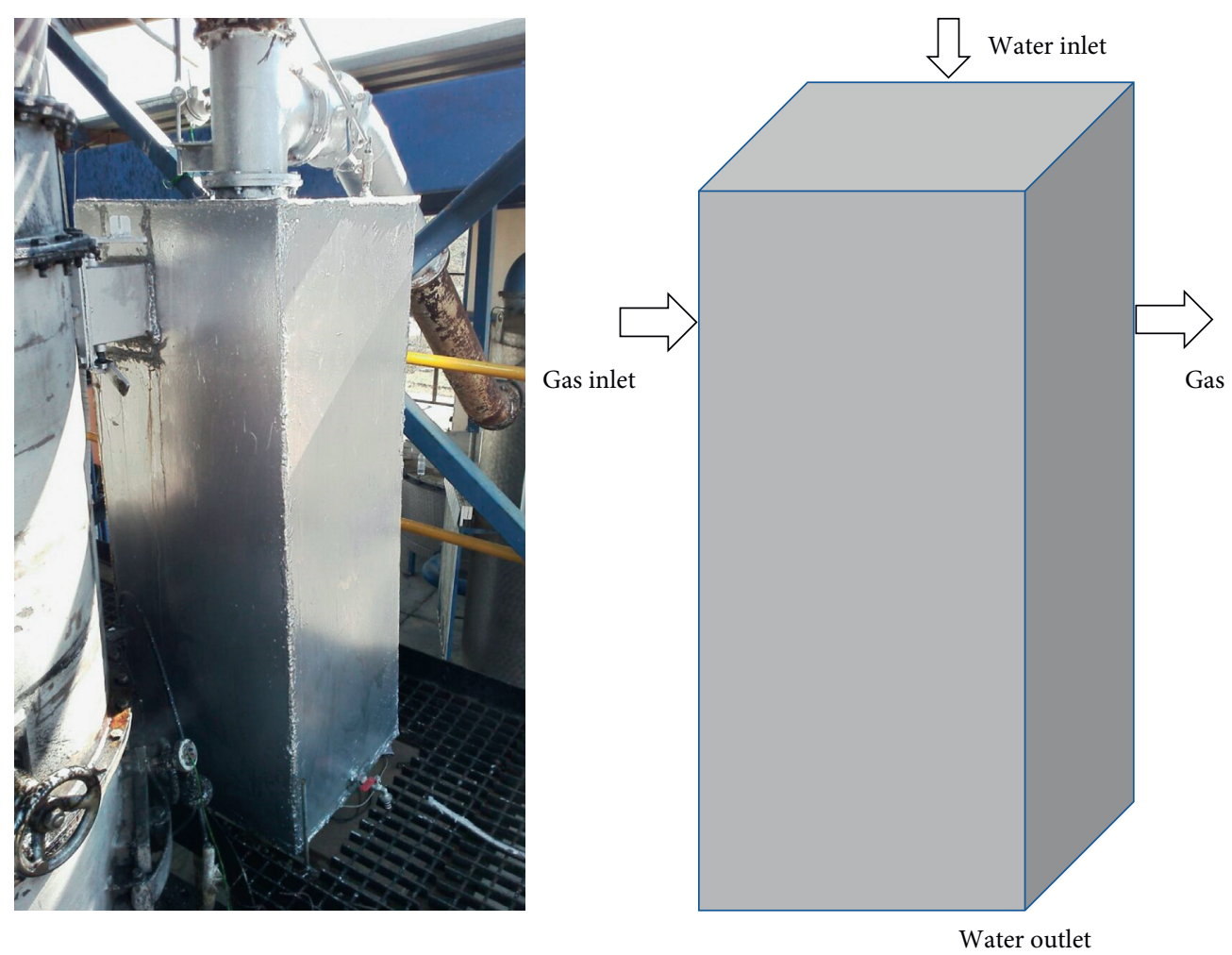

FIgURE 2: Pictorial and schematic view of the heat exchanger.

exchanger during the fabrication process to enable easy monitoring of the water temperature during the experimental process. The volume of water $\left(\mathrm{V}_{\text {water }}\right)$ that the heat exchanger could hold was calculated using

$$
\begin{aligned}
\mathrm{V}_{\text {water }} & =\mathrm{V}_{\mathrm{HE}}-\mathrm{V}_{\text {cyclone }}, \\
\mathrm{V}_{\text {cyclone }} & =\mathrm{V}_{\text {Cylinder }}+\mathrm{V}_{\text {cone }} .
\end{aligned}
$$

Here, $\mathrm{V}_{\mathrm{HE}}$ is the volume of the rectangular heat exchanger; $\mathrm{V}_{\text {cyclone }}$ is the volume of the cyclone separator; and, because the cyclone is made of a cylindrical and a conical part, its volume was determined by adding the volume of the cylindrical part $\left(\mathrm{V}_{\text {cylinder }}\right)$ and the volume of the conical part $\left(\mathrm{V}_{\text {cone }}\right)$. From (1), the volume of water that the heat exchanger could hold was found to be 267 litres. Figure 1 illustrates the schematic diagram of the gasifier unit with the integrated double pipe heat exchanger.

To evaluate the performance of the heat exchanger, the biomass gasifier was loaded with wood chips cut to sizes of $0.075 \times 0.068 \times 0.043 \mathrm{~m}$. The moisture content of the wood chips was approximately $14 \%$, which is the acceptable limit for downdraft gasifier. To initiate the gasification process, air was supplied to the gasifier through the air nozzle located at the oxidation zone using a $2 \mathrm{~kW}$ centrifugal blower. The wood chips in the gasifier were ignited through the ignition sleeve located at the reduction zone of the gasifier. The four gasification processes were initiated as soon as the wood chips were engulfed in flames. This led to the formation of syngas as the chemical composition of the wood chips reacts with the supplied air. As the syngas flows from the gasifier into the double pipe heat exchanger, coldwater stream was also pumped into the heat exchanger.
The hot syngas flows through the inner pipe whereas the cooling water flows through the annulus of the pipes. The control valves were used to adjust the direction of the water flow. In parallel flow, water was pumped in the same direction with syngas, while in counterflow, water was pumped in the opposite direction with the syngas. Two variable flow meters measuring the flow rate of fluids were mounted on the pipes. The inlet and outlet temperature of syngas and water in the parallel and counterflow configuration were monitored using type $\mathrm{K}$ thermocouples inserted at the inlet and outlet valve of the heat exchanger. The mass flow rate and temperature measurements were repeated three times, and an average value was taken for each measurement.

4.2. Performance Evaluation of the Heat Exchanger. The use of heat exchanger enhances the efficiency of a system or process. The performance of a heat exchanger is measured using important thermal parameters which include quantity of heat, also known as heat duty; overall heat transfer coefficient; log mean temperature difference (LMTD); effectiveness; and capacity ratio. The quantity of heat emitted by the syngas and absorbed by the water was determined using

$$
\begin{array}{r}
Q_{e}=\left(m C_{p}\right)_{h}\left(T_{h, i}-T_{h, o}\right), \\
Q_{a}=\left(m C_{p}\right)_{c}\left(T_{c, o}-T_{c, i}\right),
\end{array}
$$

where $m_{h}$ and $m_{c}$ are the mass flow rate of syngas and water, respectively; $C_{p h}$ and $C_{p c}$ are the specific heat capacity of syngas and water, respectively; $T_{h, i}$ and $T_{c, i}$ are the inlet 
temperature of syngas and water, respectively; and $T_{h, o}$ and $T_{c, o}$ are the outlet temperature of syngas and water, respectively.

The overall heat transfer coefficient $(U)$ is a vital performance parameter and is defined as shown in

$$
\mathrm{U}=\frac{\mathrm{Q}_{e}}{A \times \mathrm{LMTD}}
$$

where $\mathrm{A}$ is the heat transfer surface area and LMTD is the log mean temperature difference which is defined as shown in (5) for counterflow configuration:

$$
\operatorname{LMTD}=\frac{\left(T_{h, i}-T_{c, o}\right)-\left(T_{h, o}-T_{c, i}\right)}{\ln \left(\left(T_{h, i}-T_{c, o}\right) /\left(T_{h, o}-T_{c, i}\right)\right)}
$$

The effectiveness $(S)$ was determined using

$$
\mathrm{S}=\frac{C_{\max }\left(T_{c, o}-T_{c, i}\right)}{C_{\min }\left(T_{h, i}-T_{c, i}\right)}
$$

where $C_{\max }$ and $C_{\min }$ represent the maximum and minimum capacity coefficient of the fluids. The capacity coefficients are derived from the product of the mass flow rate and specific heat capacity of the fluids.

\section{Results and Discussion}

This study considered the design, fabrication, and integration of a heat exchanger into an existing gasification plant in order to recover some significant heat from the syngas as it passes through the cyclone separator. During the performance test, the rate of wood supply to the gasifier plant was approximately $180 \mathrm{~kg} / \mathrm{hr}$, and the moisture content of the wood chips was $14 \%$ on average. The performance of the integrated heat exchanger was evaluated in terms of its thermal characteristics.

5.1. Thermal Performance of the Heat Exchanger. In this study, the thermal characteristics of the designed and constructed heat exchanger were evaluated for countercurrent flow arrangement. The physical properties of the fluids passing through the heat exchanger are presented in Table 3. These physical properties helped to determine other thermal performance parameters of the heat exchanger.

The syngas density of $0.963 \mathrm{~kg} / \mathrm{m}^{3}$ recorded was determined from the molar masses and percentage composition of the individual gases that make up the syngas. Similarly, the specific heat capacity of $399 \mathrm{~J} / \mathrm{kgK}$ was determined at constant pressure from the percentage composition of the syngas. The produced syngas is composed of carbon monoxide, methane, hydrogen, carbon dioxide, and nitrogen. The specific heat capacity assisted in calculation of the quantity of heat emitted and absorbed by the thermal fluids undergoing the heat exchange. The thermal conductivity of $0.058 \mathrm{~W} / \mathrm{mK}$ obtained for the syngas is close to the range of 0.01 to $0.03 \mathrm{~W} / \mathrm{mK}$ usually reported in technical data for most gases at room temperature. However, thermal conductivity goes above the reported range of 0.01 to $0.03 \mathrm{~W} / \mathrm{mK}$ at higher temperature, which for helium gas is reported to be $0.25 \mathrm{~W} / \mathrm{mK}$
TABLE 3: Physical parameters of the fluids passing through the heat exchanger.

\begin{tabular}{lcc}
\hline Parameters & Syngas & Water \\
\hline Density $\left(\mathrm{kg} / \mathrm{m}^{3}\right)$ & 0.963 & 997.1 \\
Specific heat capacity $(\mathrm{J} / \mathrm{kgK})$ & 399 & 4186 \\
Thermal conductivity $(\mathrm{W} / \mathrm{mK})$ & 0.058 & 0.598 \\
Dynamic viscosity $(\mathrm{kg} / \mathrm{ms})$ & 0.0000076 & 0.00089 \\
\hline
\end{tabular}

at $600 \mathrm{~K}$ [15]. Thermal conduction in the syngas stems from the collisions that exist between gas molecules, which in turn leads to energy transfer. Thermal conductivity of a gas is dependent on temperature, pressure, and density of the gas. It increases with the increase in temperature and pressure. This is supported by the finding that thermal conductivity of a gaseous fluid is dependent on temperature and density at different limits [16]. The viscosity of the fluids provided information regarding the free flow of the fluids through the heat exchanger. As expected, water is more viscous than syngas; however, the viscosity of the two fluids is very low, which indicates lesser resistance to their flow during the performance test. The uncertainty for all the physical parameters in Table 3 ranged from 0.001 to 0.08 . Table 4 presents the measured temperature and mass flow rate of the fluids during the performance test.

The measured mass flow rate and temperature presented in Table 4 were used along with the physical parameters to further evaluate the performance parameters. The uncertainty in the measurement ranged from 0.001 to 0.15 for the measured temperature and mass flow rate. The parameters calculated include quantity of heat emitted by the syngas and quantity of heat absorbed by the water, heat transfer coefficient, effectiveness, and LMTD. The quantity of heat emitted by the syngas and the quantity absorbed by the water passing through the heat exchanger were evaluated using (5) and (6). Figure 3 shows the overall heat transfer coefficient for counterflow and parallel flow configurations as a function of variable mass flow rate of water.

It is noted from Figure 3 that as the mass flow rate of cooling water increased from $0.02 \mathrm{~kg} / \mathrm{sec}$ to $0.07 \mathrm{~kg} / \mathrm{sec}$, the overall heat transfer coefficient equally increased from a value of $7.89 \mathrm{~W} / \mathrm{m}^{2} \mathrm{~K}$ to $10.06 \mathrm{~W} / \mathrm{m}^{2} \mathrm{~K}$ for parallel flow and from $8.03 \mathrm{~W} / \mathrm{m}^{2} \mathrm{~K}$ to $10.20 \mathrm{~W} / \mathrm{m}^{2} \mathrm{~K}$ for counterflow. The rise in overall heat transfer coefficient recorded in both flows can be attributed to an increase in flow velocity, which caused an increase in turbulence. This in turn led to an increase in heat transfer rate. Flow velocity also increased the Reynold's number of the fluid that has a direct relation with Nusselt number according to Dittus-Boelter equation for turbulent flow. The increase in turbulence forces the fluid against the wall of the heat exchanger, and the greater the volume of fluid in contact with the wall, the greater the absorption of heat energy by the fluid. A similar trend of increase was recorded in another study, where the mass flow rate of water increased from $0.4 \mathrm{~kg} / \mathrm{sec}$ to $0.7 \mathrm{~kg} / \mathrm{sec}$. The overall heat transfer coefficient of the heat exchanger increased from $129.2 \mathrm{~W} / \mathrm{m}^{2} \mathrm{~K}$ to $178.9 \mathrm{~W} / \mathrm{m}^{2} \mathrm{~K}$ with water used as both fluids [17]. Moreover, Osueke et al. [18] reported that an increase in mass flow rate of fluid caused a corresponding increase in overall heat transfer coefficient for a parallel plate heat 
TABLE 4: Steady state parameters of the fluid passing through the heat exchanger.

\begin{tabular}{lccc}
\hline Parameters & Unit & Inlet & Outlet \\
\hline Syngas flow rate & $\mathrm{kg} / \mathrm{sec}$ & 0.037 & 0.037 \\
Water flow rate & $\mathrm{kg} / \mathrm{sec}$ & 0.020 & 0.020 \\
Syngas temperature & ${ }^{\circ} \mathrm{C}$ & 350 & 269.4 \\
Water temperature & ${ }^{\circ} \mathrm{C}$ & 20 & 65.1 \\
\hline
\end{tabular}

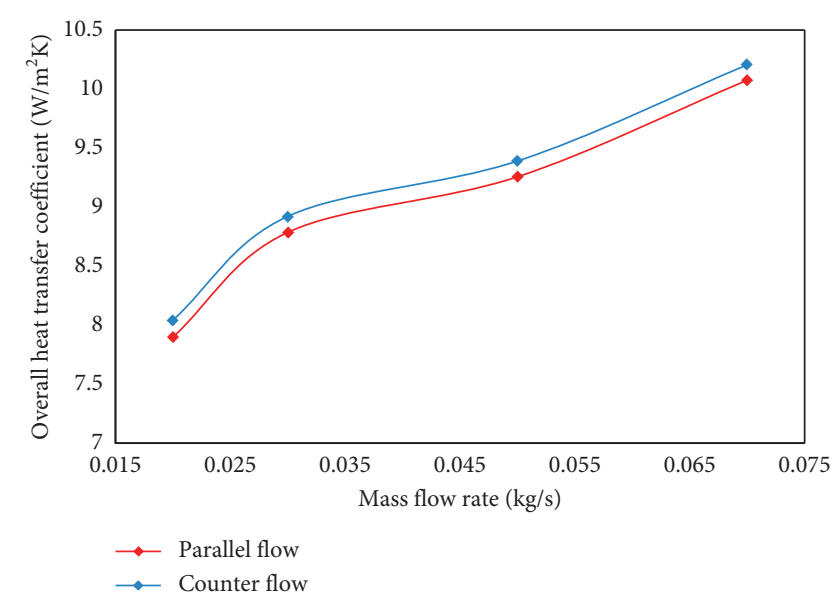

Figure 3: Overall heat transfer coefficient at different mass flow rates.

exchanger. It is also important to note that overall heat transfer coefficient can be improved through some mechanisms such as air bubble injection into the tubes and insertion of fins [6], whereas fouling impacts negatively on the overall heat transfer coefficient [19]. However, the type of fluid that is undergoing the heat exchange usually affects the overall heat transfer coefficient. Additionally, the heat exchanger effectiveness was evaluated with variation in mass flow rate as shown in Figure 4.

It can be noted from Figure 4 that mass flow rate has a direct influence on the double pipe heat exchanger effectiveness. The heat exchanger effectiveness increases with the increase in the flow rate in each case. For the water mass flow rate between $0.02 \mathrm{~kg} / \mathrm{sec}$ and $0.07 \mathrm{~kg} / \mathrm{sec}$, the effectiveness increases from 0.43 to 0.54 . This is comparable to the effectiveness range of $0.50-0.58$ recorded for a double pipe heat exchanger with and without twisted inserts [20]. Sen and Agrawal [21] reported effectiveness ranges of 0.29 to $0.36,0.41$ to $0.55,0.44$ to 0.48 , and 0.32 to 0.43 for plain tube, helical twisted wire tube, twisted clip, and threaded tubes of a double pipe heat exchanger. The optimum effectiveness of 0.55 reported in the above study compared well with the optimum effectiveness of 0.54 obtained in the current study. The later study focused on enhancing the heat transfer parameters of a double pipe heat exchanger through the creation of turbulence in the inner and outer tube. Thus, it is evident that effectiveness of a double pipe heat exchanger can be improved through creation of turbulence. Simhadri et al. [20] achieved this by creating turbulence in the hot fluid channel using the twist inserts at hot fluid and cold fluid flow rate of $0.032 \mathrm{~kg} / \mathrm{sec}$ and $0.04 \mathrm{~kg} / \mathrm{sec}$, respectively. The mass flow rates for the hot

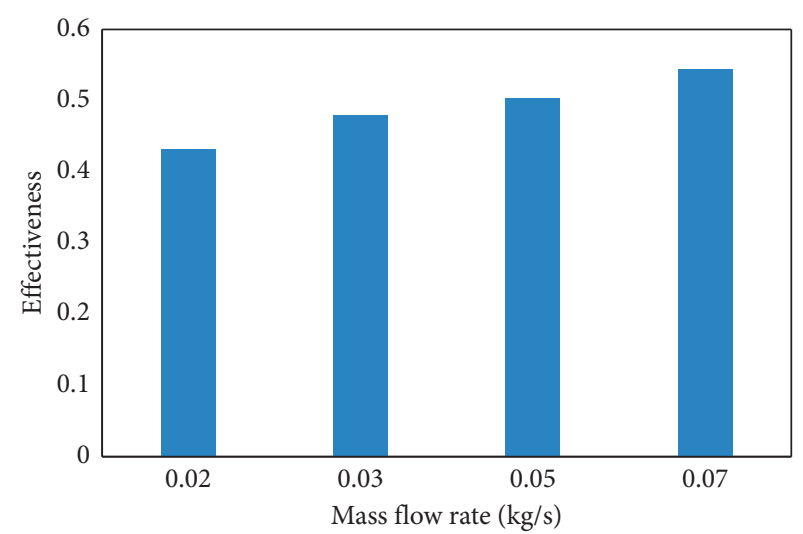

FIGURE 4: Variations of heat exchanger effectiveness with mass flow rate.

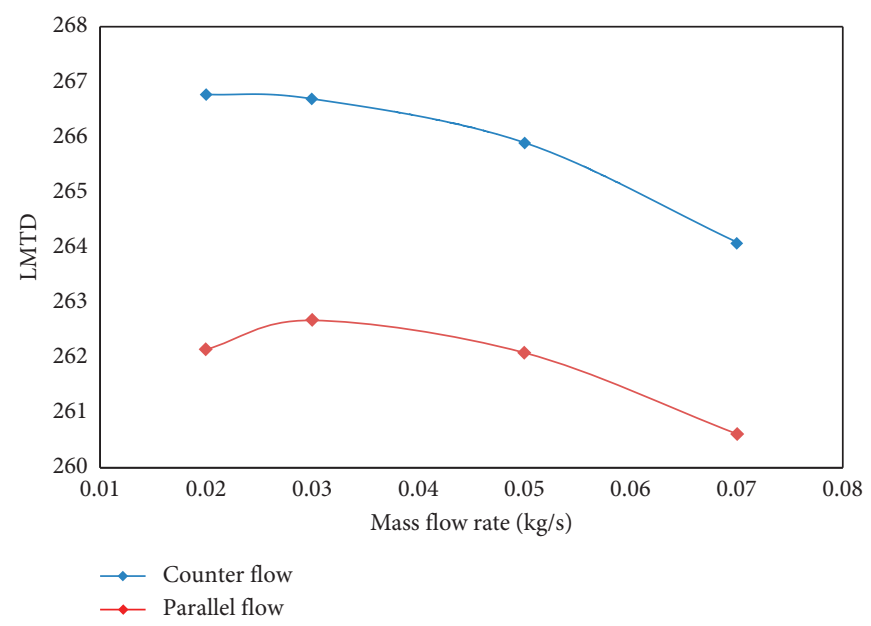

FIGURE 5: Log mean temperature difference versus mass flow rate.

fluids in both studies above are similar but differed in the type of fluids used. Also, effectiveness can be improved by increasing the number of transfer units [22]. Figure 5 shows the LMTD for counterflow and parallel flow configuration under different flow rates.

Log mean temperature difference (LMTD) is a vital parameter as it determines the temperature driving force for heat transfer in a heat exchanger. Figure 5 shows that the LMTD, for counterflow and parallel flow configurations, dropped with an increase in mass flow rate. However, it is observed that LMTD for parallel flow configuration lags behind counterflow by approximately $1.75 \%$ for the entire mass flow rate. In another study, the LMTD for parallel flow was equally reported to lag behind counterflow configuration at higher flow rate [22]. This can be explained by the relative direction of the syngas and water (fluids) flow that influences the required area for heat transfer. Also, noting the inverse relationship that exists between the heat transfer area and LMTD, the declining trend of LMTD can be explained [23]. Besides mass flow rate, the hot syngas inlet temperature was also found to have a direct influence on LMTD. 


\section{Conclusions}

In this study, a tubular heat exchanger of double pipe type was designed, constructed, and integrated into an existing biomass gasification plant for the purpose of recovering heat from the syngas exiting the gasifier at a temperature of approximately $350^{\circ} \mathrm{C}$. The custom-built heat exchanger has a water holding capacity of 267 litres. The performance of the heat exchanger was measured during the operation of the gasification plant with a wood supply rate of $180 \mathrm{~kg} / \mathrm{hr}$ into the gasifier. From the findings obtained in relation to the heat exchanger performance test carried out, the following conclusions were drawn:

(1) The overall heat transfer coefficient was increased from a value of $7.89 \mathrm{~W} / \mathrm{m}^{2} \mathrm{~K}$ to $10.07 \mathrm{~W} / \mathrm{m}^{2} \mathrm{~K}$ for parallel flow and from $8.03 \mathrm{~W} / \mathrm{m}^{2} \mathrm{~K}$ to $10.20 \mathrm{~W} / \mathrm{m}^{2} \mathrm{~K}$ for counterflow configurations.

(2) Counterflow was approximately $14 \%$ more effective than parallel flow. This was attributed to the increase in flow velocity that caused an increase in turbulence, which in turn led to an increase in heat transfer rate.

(3) In addition, the log mean temperature difference for parallel flow configuration lags behind counterflow by approximately $1.75 \%$.

(4) The maximum quantity of heat energy $(15.1 \mathrm{~kJ})$ was emitted by the syngas, and approximately $8.0 \mathrm{~kJ}$ was recovered with the installation of the double pipe heat exchanger. Hence, integration of a heat exchanger with double piping system is about $50 \%$ efficient in the recovery of heat from the syngas in the Johansson downdraft gasifier.

\section{Data Availability}

The datasets generated and/or analyzed during the current study are not publicly available, because some of the datasets are still to be used for future publications but are available from the corresponding author on reasonable request.

\section{Disclosure}

The funders had no role in the design of the study; in the collection, analysis, or interpretation of data; in the writing of the manuscript; or in the decision to publish the results.

\section{Conflicts of Interest}

The authors declare that they have no conflicts of interest regarding the publication of this paper.

\section{Acknowledgments}

This article was made possible by the financial support from Govan Mbeki Research and Development Centre of University of Fort Hare. The authors thank Energy and Water Sector Education and Training Authority (EWSETA), South Africa, and ESKOM that provided the gasification plant alongside the support of University of Fort Hare.

\section{References}

[1] N. A. Tali, Y. Almahdawi, M. Ahmed, and R. Alsaeedi, "Computational analysis of double-pipe heat Excanger with Naofluid," Journal of Thermal Engineering Istanbul Turkey, vol. 4, 2017.

[2] V. Kirsanovs, D. Blumberga, K. Karklina et al., "Biomass Gasification for district heating," Energy Procedia, vol. 113, pp. 217-223, 2017.

[3] H. S. Patel and R. N. Makadia, "A review on performance evaluation and CFD analysis of double pipe heat exchanger," Indian Journal of Research, vol. 2, 2013.

[4] C. K. Pardhi and P. Baredar, "Performance improvement of double pipe heat exchanger by using turbulator," International Journal of Engineering Science \& Advanced Technology, vol. 2, no. 2, pp. 881-885, 2012.

[5] M. Kannan, S. Ramu, S. Santhanakrishnan, G. Arunkumar, and M. Vivek, "Experimental and Analytical comparison of heat transfer in double pipe heat exchanger," International Journal of Automobile Engineering Research and Development, vol. 3, pp. 1-10, 2012.

[6] M. M. Heyhat, A. Abdi, and A. Jafarzad, "Performance evaluation and exergy analysis of a double pipe heat exchanger under air bubble injection," Applied Thermal Engineering, vol. 143, pp. 582-593, 2018.

[7] L. D. Mafu, H. W. J. P. Neomagus, R. C. Everson, G. N. Okolo, J. R. Strydom, and J. R. Bunt, "The carbon dioxide gasification characteristics of biomass char samples and their effect on coal gasification reactivity during co-gasification," Bioresource Technology, vol. 258, pp. 70-78, 2018.

[8] S. K. Sansaniwal, K. Pal, M. A. Rosen, and S. K. Tyagi, "Recent advances in the development of biomass gasification technology: a comprehensive review," Renewable and Sustainable Energy Reviews, vol. 72, pp. 363-384, 2017.

[9] M. A. Chawdhury and K. Mahkamov, "Development of a small downdraft biomass gasifier for developing countries," Journal of Scientific Research, vol. 3, pp. 51-64, 2013.

[10] A. Kumar, D. Jones, and M. Hanna, "Thermochemical biomass gasification: a review of the current status of the technology," Energies, vol. 2, no. 3, pp. 556-581, 2009.

[11] W. Pruksakit, C. Dejterakulwong, and S. Patumsawad, "Performance prediction of a downdraft gasifier using equilibrium model: effect of different biomass," in Proceedings of the 5th International Conference on Sustainable Energy and Environment (SEE: Science, Technology and Innovation for ASEAN Green Growth, pp. 19-21, Bangkok, Thailand, 2014.

[12] A. K. Jain, "Biomass gasification under oxygen medium," Journal of Agricultural Engineering, vol. 36, no. 3, pp. 27-31, 1999.

[13] K. Elsayed and C. Lacor, "The effect of cyclone inlet dimensions on the flow pattern and performance," Applied Mathematical Modelling, vol. 35, no. 4, pp. 1952-1968, 2011.

[14] N. Nwokolo, S. Mamphweli, and G. Makaka, "An investigation into heat recovery from the surface of a cyclone dust collector attached to a downdraft biomass gasifier," Applied Thermal Engineering, vol. 98, pp. 1158-1164, 2016.

[15] B. A. Younglove and H. J. M. Hanley, "The viscosity and thermal conductivity coefficients of gaseous and liquid argon," Journal of Physical and Chemical Reference Data, vol. 15, no. 4, pp. 1323-1337, 1986.

[16] B. Le Neindre, G. Lombardi, P. Desmarest et al., "Thermal conductivity of gaseous and liquid n-hexane," Fluid Phase Equilibria, vol. 474, pp. 60-75, 2018. 
[17] M. P. Murugesan and R. Balasubramanian, "The effect of mass flow rate on the enhanced heat transfer characteristics in A corrugated plate type heat exchanger," Research Journal of Engineering Sciences, vol. 1, no. 6, pp. 22-26, 2012.

[18] C. O. Osueke, A. O. Onokwai, and A. O. Adeoye, "Experimental investigation on the effect of fluid flow rate on the performance of a parallel flow heat exchanger," International Journal of Innovative Research in Advanced Engineering, vol. 2, pp. 2349-2163, 2015.

[19] E. T. Tamayo, E. J. Diaze, M. P. Cedeno, C. L. Vargas, S. G. Peralta, and M. A. Falconi, "Overall heat transfer coefficients pressure drop and power demand in plate heat exchangers during the ammonia liquor cooling process," International Journal of Mechanics, vol. 10, 2016.

[20] K. Simhadri, G. V. D. Mohan, and P. Sai Chaitanya, "Comparison of overall heat transfer coefficient value of double pipe heat exchanger without and with various twisted inserts of different twist ratios," Journal of Mechanical and Civil Engineering, vol. 12, pp. 115-124, 2015.

[21] D. Sen and A. Agrawal, "Enhancing the heat transfer parameters in double pipe heat exchanger by creating turbulence in inner and outer tube," International Journal for Research in Applied Science \& Engineering Technology (IJRASET), vol. 6, pp. 1-4, 2018.

[22] V. Kannojiya, R. Gaur, P. Yadav, and R. Sharma, "Performance investigation of a double pipe heat exchanger under different flow configuration by using experimental and computational technique," Archive of Mechanical Engineering, vol. 65, pp. 1-15, 2018.

[23] M. I. Stewart, "Heat transfer theory: Surface production operations," Surface Production Operations, vol. 2, no. 6, Article ID 061102, 2014. 